\title{
NOTAS SOBRE LA OBRA CIENTÍFICA DE COSERIU (6)
}

\author{
JOSÉ POLO \\ (Universidad Autónoma de Madrid)
}

II ARQUITECTURA DE LA LENGUA 2: paréntesis que desembocará en Coseriu (4)

D

$\overline{\text { VICENTE GARCÍA DE DIEGO: } 1926 \text { Y ALEDAÑOS }}$

0

En la entrega anterior llegamos hasta 1925 inclusive. Ahora, dentro del panorama telegráfico que voy presentando en torno a los ejes diastrático y diafásico, me detengo en una fecha clave y un autor «clásico por antonomasia» en estos asuntos. Pero, según anuncio, no se trata solamente de ese año emblemático, sino de otros más, anterior y posteriores, todo lo cual conforma la visión, sistemática e integradora, de don Vicente García de Diego sobre estas cuestiones. Enseguida podremos comprobar cómo la preocupación de nuestro autor español por «lo social» arranca ya de sus primeros trabajos, aunque en mi investigación me voy a limitar a las referencias sobre ello que aparecen en sus libros. De otro modo: un estudio pormenorizado del conjunto de su obra podría seguramente añadir datos complementarios de los que aparecerán aquí, aunque pienso que la armazón de su universo conceptual se halla perfectamente dibujada en el recorrido fundamental que comienza en este momento... 


\section{Una vieja aproximación: 1914}

En efecto: se trata de su libro Elementos de gramática histórica castellana, Tipografía de «El Monte Carmelo», Burgos, 1914 (antecedente de su obra más conocida de 1951/1961/1970: véase más adelante). Voy a citar del prólogo (páginas 7-8) y de la introducción (págs. 15-18). Comenzaré, arrancando desde atrás conceptualmente, con el eje diacrónico, mostrando cómo se supera en la práctica la dicotomía saussuriana, para desembocar luego en los movimientos internos de los ejes diastrático y diafásico, hablando en términos modernos, fundamentalmente coserianos. Los dos fragmentos que transcribiré en primer lugar, sección A, corresponden al primero y último párrafos, respectivamente, del susodicho prólogo. Préstesele atención a todo ello (modernizo la acentuación y dejo intacta la puntuación):

$$
\frac{A}{1 /[\text { pág. }] 7}
$$

Me propongo simplemente escribir un breve bosquejo de nuestra gramática, ofrecer un manual, resumen y avance a la vez de un estudio más amplio que preparo, en el cual se ordenen algunos materiales ajenos, reunidos con observaciones mías. Es ya inútil insistir en que todo estudio gramatical de una lengua de abolengo literario no puede concretarse al momento actual, ya que tan preciso nos es conocer la lengua de Cervantes y Santa Teresa por ejemplo como la de nuestros días, so pena de condenarnos a no poder leer jamás debidamente nuestros clásicos.

\section{$2 / 8$}

Acaso hubiera sido más científico separar completamente la gramática práctica de la histórica: pero he creído que si a alguno pueden ofender las nociones demasiado elementales y a otros parecer superfluas las observaciones de carácter histórico, a la generalidad no será enojoso ver reunido cuanto le sirva para conocer la lengua actual y para penetrar en nuestro tesoro literario.

$$
\frac{B}{3 / 7}
$$

Tampoco será preciso defender por qué me limito a exponer históricamente los hechos, clasificándolos cuando más en formas y construcciones vulgares y cultas, sin rechazar ninguna que el uso general haya sancionado, sin enmendar las absurdas, ni condenar ni posponer las menos lógicas, sin profanar textos ni soñar erratas de impresión, sin someter en fin a un menguado criterio de filosofía fácil la sutilísima filosofía del lenguaje. He querido en una palabra huir del camino de nuestros gramáticos filósofos, que, 
empeñados en encerrar en los cánones de una gramática rudimentaria de la lengua actual la admirable complejidad de nuestro idioma clásico, fulminaban severos anatemas contra cuanto no encajaba en sus estrechos moldes. Hay que convenir en que si en la lengua actual podemos tildar de incultas las particularidades, arcaísmos o innovaciones de la lengua popular, no podemos rechazar con el estigma de incorrectas o ilógicas cuantas son patrimonio de la lengua común, y en la lengua histórica cuantas tienen la sanción del uso corriente de su tiempo.

\section{$4 / 7-8$}

Pongo especial empeño en señalar la supervivencia de muchos fenómenos clásicos, y aun de la lengua primitiva, en nuestra lengua actual, especialmente en la hablada, donde persisten, ya lozanos, ya petrificados, no pocos de Ios que son tenidos por arcaicos. También apelo con frecuencia al testimonio de la lengua viviente para dar fe de diversos fenómenos (palabras y fenómenos fonéticos, morfológicos y sintácticos), que por no hallarsc, o no ser frecuentes en la lengua escrita, no son registrados en los diccionarios ni en las gramáticas: omisión disculpable en los filólogos extraños que trabajan sobre lextos literarios, pero no en los nuestros que por desdén han prescindido de este tan fértil e inexplorado campo.

\section{0-2}

El \$9, págs. 16-18, de «Introducción», se titula El castellano vulgar, al que delïne e ilustra con fenómenos de tipo fonético, morfológico, léxico y sintáctico. Es importante señalar la presencia, ya en 1914, de ese apartado, que va a mantener, incluso con el mismo nombre, en obras suyas posteriores. Dejemos constancia, antes de pasar a otro lugar, de cómo define el concepto atrás cnunciado. Dice ( $\$ 9$, págs. 16-17): «El castellano vulgar es el conjunto de fenómenos que discrepan de la lengua literaria común considerada en la escritura y en la pronunciación enfática. Como en las demás lenguas vulgares[,] estos fenómenos se hallan principalmente, pero no privativamente, en el vulgo: unos son rústicos, otros populares, otros familiares, algunos de la conversación descuidada de las personas aun las más cultas, y muchos de carácter local, que, aunque transciendan a la escritura, no son admitidos en la lengua común». Luego viene, tal como señalaba, la ilustración, suficiente, de dicho concepto. 


\section{El consabido «1926»}

En la entrega tercera de esta serie (9/1993), en II-2-A-3, fragmento 19/16-17, pág. 292, citaba yo a P. PASSY, que hablaba de «dialectes locaux», de «dialectes sociaux» y de «dialectes occasionnels». Posteriormente, en el número 11/1996, quinta entrega, II-2-C-B3-4, fragmento 1, A. DAUZAT hablaba de «dialectos locales o sociales [cursiva mía] según la feliz denominación de Paul Passy». Bien: recuerdo estos datos para que, al escuchar a García de Diego, pensemos si se trata de innovación terminológica, o incluso conceptual, de él o si la tomó de alguno de los dos autores nombrados, ninguno de los cuales parecía ser desconocido para el estudioso español.

Bien: estamos ya con don Vicente García de Diego. En 1926 se publica en Ávila (Tipografía y Encuadernación de Senén Martín) Problemas etimológicos: «discurso leído ante la Real Academia Española en el acto de su recepción por [...] y contestación de D. Ramón Menéndez Pidal, Director de la Real Academia, el día 7 de noviembre de 1926». Dentro del apartado v, La etimología vitalista, págs. 22-26, nos dice (pág. 23; modernizo la acentuación):

La etimología vitalista no considera el lenguaje en la unidad artificiosa de la lengua oficial, sino como una vastísima complejidad de dialectos mutuamente influidos y como una superposición de dialectos sociales [cursiva mía]. «Si no buscamos, dice Jaberg [omito la nota 2][,] una falsa simplificación, la evolución de las palabras se ofrece en una complicación desconcertante para el que las miraba desde el punto de vista de la lingüística clásica; mas esa es la realidad, y ante ella los métodos simplicistas de la investigación etimológica tienen que fracasar».

Aquí está ya, puede observarse, el pasaje clásico del discurso académico de Vicente García de Diego. Pero en el mismo texto se encuentran otras referencias a los hechos sociales, etc., en el lenguaje, lugares que deseo mostrar como parte de la línea sostenida de preocupación por los ejes diastrático y diafásico en nuestro autor y, específicamente en el caso de ahora, para que se vea que no se trata de un pasaje aislado, sino que él respiraba esa clase de ideas y que aparecen de modo natural en cualquier rincón de su dilatada obra, histórica y dialectal. Veamos (pág. 14, dentro del apartado IV, La etimología fonética y la idealista):

Los mismos sostenedores del criterio cerrado y dogmático del foneticismo etimológico no sólo tienen que rendirse ante el hecho de las excepciones, de 
las divergencias dialectales y sociales [cursiva mía], sino que apelan en sus trabajos prácticos a explicaciones no materiales[...].

Como preparación del terreno para el siguiente epígrafe, ficharé aquí dos trabajos de nuestro autor que, aun no siendo directamente de corte «social», representan el mismo espíritu de visión matizada, antimecánica, de los hechos del lenguaje. Me refiero a: I) «Dialectalismos», en Revista de Filología Española, III/1916, págs. 301-318, y 2) «El castellano como complejo dialectal y sus dialectos internos», en la revista acabada de mencionar, XXXIV/1950, págs. 107124.

\section{Llega 1951 (con sus prolongaciones)}

En efecto: en ese año publica nuestro autor Gramática histórica española (Gredos, Madrid), con una segunda edición en 1961 y una tercera en 1970 (a través de la cual citaré). Dentro de «Introducción», págs. 10-31, contamos con el epígrafe El castellano vulgar (compárase atrás 1/0-2), págs. 21-31. Reproduzco la parte inicial, previa a la ilustración, para que sirva de contráste con la definición o explicación de dicho concepto en su obra de 1914 (véase atrás $1 / 0-I$ ). Cito de las páginas 21-22:

La lengua vulgar tiene gran difusión y una cierta coincidencia en las diversas regiones castellanas, no sólo de la Península, sino de los pueblos americanos. Por ser subestimado frente a la lengua culta, el castellano vulgar peninsular ha sido muy imperfectamente estudiado. En los pueblos americanos, tomándolo como hecho diferencial, ha sido recogido con más diligencia, y en estos estudios se aprecia que mucho de lo que se creía característico en su fonética, léxico y gramática, y como innovación nacionai, nо es sino supervivencia de hechos que viven en los fondos rurales o incultos de España. Dentro de la Península este castellano vulgar es en especial, con algunas variantes, fondo común del pueblo rústico y también, en parte, del bajo pueblo ciudadano, y aun del habla descuidada de la gente culta en muchos trazos fonéticos. Este castellano vulgar en algunos elementos es coincidente con elementos regionales próximos; fundamentalmente es el habla del pueblo rural y bajo de ambas Castillas, que en la expansión de este idioma ha penetrado y arraigado en las regiones cuyo dialecto fue globalmente eliminado (reino de León, Extremadura, Andalucía, Murcia y Aragón) y que en gran parte se acepta aun en las regiones con dialecto vivo (Asturias, Pirineo aragonés, etc.). Esta habla popular, tan poco apreciada, o recogida, a lo más como clemento pintoresco en la literatura, sin criterio lingüístico, merecía, por su importancia, un estudio fundamental. Para el estudio de la lengua vulgar son útiles los estudios y diccionarios de las distintas regiones españolas y los 
de las hablas americanas. Un elemento diferencial de gran trascendencia es el léxico. Son numerosas las palabras que sólo usa el vulgo y numerosas las que teniendo uso normal en el vulgo trascienden en ciertos casos a ciertas personas cultas.

En 1946 publica nuestro autor Manual de dialectología española (Ediciones Cultura Hispánica, Madrid), con una segunda edición en 1959 (y una tercera, merä impresión, en 1978), en que -repito: 1959-, bajo un nuevo apartado, Dialectos internos verticales, págs. 369-377, reproduce el epígrafe El castellano vulgar de su obra directamente histórica, repetición textual precedida de unas líneas introductorias que rezan así (pág. 369):

Son dialectos verticales las modalidades estables de las hablas de las distintas clases sociales. Los más importantes son el habla culta y el habla vulgar; pero hay otras peculiaridades importantes, como son las hablas técnicas de las profesiones y de los oficios, que suelen incluirse en buena parte en los diccionarios comunes [compárese, en entrega posterior, la visión de Julio Casares que late en esas últimas palabras], las jergas arraigadas tradicionalmente en algunos oficios, las jergas ocultistas de los pícaros y las jergas limitadas y cambiantes que surgen ocasionalmente en algunos medios.

\section{Otro 1951}

$0-1$

El texto más citado de García de Diego en relación con lo social del lenguaje es seguramente el de 1926; al menos, resulta el «fundacional» para la historia interna del desarrollo de sus ideas en este punto. Ya hemos visto cómo su procupación arranca de mucho antes (por muy tarde, 1914: véase atrás 1/0-l). Pero hay todavía un frente, menos conocido y reseñado en forma dispar, que es el extenso volumen Lingiuística general y española (CSIC, Madrid, 1951). En la bibliogralía (págs. 651-656) están A. Dauzat, P. Passy, A. Meillet, H. Paul, W. Wartburg, J. Vendryes, etc., de los que pudo haber bebido, aparte sus propias y vicjas ideas al respecto, para «inspirarse» 0 «ayudarse» en su matizada persistente visión del microcosmos de los «dialectos sociales». Pero, en todo caso, dentro del denominado libro tercero, El lenguaje. Sus clases, tenemos los capítulos V, Lenguaje social (págs. 294-315), y VI, Lenguaje ontológico y axiológico (páginas 316-371).

\section{$0-2$}

Transcribo ahora el nombre de las subdivisiones de esos dos ilustradores capílulos: V: Lengua; Estratos y círculos; Lenguaje generacional; Lenguaje de los 
sexos; Lengua literaria; Hiperurbanismo; Lengua familiar; Lengua coloquial; Lengua vulgar; Lengua jergal; Tecnicismos; VI:Conceptos del lenguaje axiológico; Conceptos de puro conocimiento; Conceptos de pura valoración; Conceptos mixtos; Conceptos con morfema axiológico; Medios de expresión del lenguaje axiológico; Presentación y exclamación; Segmentación y reticencia; Orden, concatenización y contraste; Pleonasmo; Reduplicación y repetición; Elipsis; Acumulación; Meliorativos; Peyorativos; Ponderación; Hipérbole; Afectividad; Disfemismo; Humorismo; Ironía; Retruécano; Interdicción; Eufemismo; Interdicción mística y supersticiosa; Lenguaje estético; Lenguaje respetuoso. El capítulo VII de esa tercera parte del volumen se titula Lenguaje intelectual $e$ inductivo, correlato necesario del que le precede, menos neutro.

\section{$0-3$}

Pero 195 I fue año generoso con Vicente García de Diego o él lo fue con nosotros los lectores, pues también se publicó Lecciones de lingüística española («conferencias pronunciadas en el Ateneo de Madrid»): Gredos, Madrid. De este volumen nos intercsan, complementariamente a lo expuesto atrás, los capítulos 1 , La afectividad en el lenguaje, III, La propiedad lingüística, VI, La imprecisión, sino fatal del lenguaje, y VII, Opulencia y miseria del lenguaje.

Preparado ya el terreno con los tres frentes que preceden, voy a transcribir diversos pasajes del mencionado capítulo $\mathrm{V}$ del primer libro de 1951, en los que se nos muestra, una vez más, en forma sistemática la preocupación de nuestro autor por lo social y estilístico (ejes diastrático y diafásico). Como antes había sugcrido, haría falta un estudio específico para dilucidar el origen de las ideas «Sociolingüísticas» de nuestro autor en este grueso volumen, pero, en todo caso, préstesele atención a lo que aparecerá porque se trata de textos menos conocidos de su obra conjunta. Comience, pues, el desfile de los anunciados pasajes...

\section{1/295-296}

La lengua, como unidad perfecta, es una abstracción. La realidad son las hablas individuales, semejantes, según la expresión de PASSY [relieve lipográfico mío], a las hojas de un árbol, todas en apariencia iguales, todas algo diferentes. Luego existen en la nación las hablas locales y regionales, con variantes notables aun en aquellos idiomas que dan una impresión de unidad. Por último se ofrecen en la lengua las variantes de los distintos estratos sociales y de los distintos grupos de la actividad humana, de las distintas profesiones y oficios, de las distintas edades y sexos, y de las variantes jergales, que viven o se producen en el seno de la lengua común [compárese, una vez más, Julio CASARES, 1950, Introducción a la lexicografía moderna]. Asíl.] bajo la unidad aparente de una lengua se nos ofrecen en una 
investigación atenta todas las antinomias regionales y sociales de los distintos grupos que integran la nación. Como hemos dicho, la lengua es una suma teórica de las hablas individuales con una apariencia de unidad, dentro de la infinita variedad que el ojo escrutador de la ciencia descubre.

\section{2/296}

La pronunciación no es uniforme en todo el territorio. Los sonidos o el tono tienen variantes geográficas en toda lengua de alguna extensión. Entre la lengua hablada y la escrita hay diferencias graves. Donde no pesa la tradición y la reglamentación gramatical, la diferencia es menor; pero nunca la escritura representa del todo la lengua hablada. Las voces no tienen los límites geográficos de la lengua. Muchas son regionales o provinciales, muchas tienen uso preferente en una región y postergado en otra; y las flexiones ofrecen variantes locales. Internamente, la lengua no es uniforme entre los literatos y el vulgo, que tiene fonética distinta y modismos peculiares, constituyendo un dialecto social [cursiva mía], en parte coincidente con otros dialectos geográficos. La lengua es un florilegio. Lo más certero o gracioso es recogido por el jurado popular permanente, que selecciona según sus gustos. La lengua social es una creación acumulada. Es la suma de las creaciones seleccionadas durante siglos en renovación poco sentida, pero incesante. Es la obra mancomunada que nos legaron nuestros antepasados y que nosotros continuamos transmitiéndola como antorcha viva a los que en el camino de la vida han de sucedernos.

\section{$3 / 301$}

Entre la condición de las personas y los modos del lenguaje hay una correlación fundamental en los distintos idiomas. En todas las lenguas de notable cultura se han sentido las modalidades sociales, y se dan a su lado las lenguas de grupos. No quiere decir que las variantes coincidan exactamente con las diferencias sociales, que cada cuerpo social tenga su habla especial, pero sí que ciertas modalidades características predominan en tal grupo de la sociedad. La lengua general es una mera realidad tipográfica en el Diccionario. En la realidad esa lengua general no existe, porque ninguna colectividad ni individuo la posee. Aunque toda lengua es individual y, como la fisonomía, no es exactamente igual en dos individuos, existe una comunidad prácticamente indiferenciada en el grupo social de cada individuo, lo que hace posible la mutua comprensión. La comunidad es menor en otros grupos sociales, que sin embargo se comprenden. Las diferencias se aprecian, aunque sólo los técnicos lingüistas podrían puntualizarlas.

(continuará) 